Brazilian Journal

of Chemical

ISSN 0104-6632

Engineering

Printed in Brazil

www.scielo.br/bjce

Vol. 34, No. 04, pp. 937 - 947, October - December, 2017

$($ (c) $)$ EY

dx.doi.org/10.1590/0104-6632.20170344s20160225

\title{
PRETREATMENTS AND ENZYMATIC HYDROLYSIS OF SUGARCANE BAGASSE AIMING AT THE ENHANCEMENT OF THE YIELD OF GLUCOSE AND XYLOSE
}

\author{
A. de A. Guilherme ${ }^{1}$, P. V. F. Dantas ${ }^{1}$, J. C. J. Soares ${ }^{1}$, E. S. dos Santos ${ }^{1}$, \\ F. A. N. Fernandes ${ }^{2, *}$ and G. R. de Macedo ${ }^{1}$ \\ ${ }^{1}$ Universidade Federal do Rio Grande do Norte, Departamento de Engenharia Química, Av. Senador Salgado Filho, 3.000, Campus \\ Universitário, Lagoa Nova, Bloco 16, Unidade II, 59078-970 Natal - RN, Brazil. \\ ${ }^{2}$ Universidade Federal do Ceará, Departamento de Engenharia Química,Campus do Pici, Bloco 709,60440-900 Fortaleza - CE, Brazil. \\ Corresponding author:Fabiano André Narciso Fernandes, Universidade Federal do Ceará, Departamento de Engenharia Química, Campus do \\ Pici, Bloco 709, 60440-900 Fortaleza - CE, Brazil. \\ *E-mail: fabiano@ufc.br; Phone: +558533669611; Fax +558533669610.
}

(Submitted: April 12, 2016; Revised: July 6, 2016; Accepted: July 19, 2016)

\begin{abstract}
This work studied the enzymatic hydrolysis of sugarcane bagasse aiming at the production of glucose and xylose. The bagasse was subjected to two different pretreatments: combined acid and alkalinepretreatment and hydrogen peroxidepretreatment. The enzymatic hydrolysis was optimized and a kinetic study was carried out in a stirred tank reactor (STR) in batch mode. Optimal conditions were obtained by subjecting the bagasse to the hydrogen peroxide pretreatment followed by enzymatic hydrolysis. The addition of xylanases to the enzymatic mixture improved the production of fermentable sugars by $48 \%$.
\end{abstract}

Keywords: cellulose; lignocellulose; glucose; xylose; enzymatic hydrolysis; pretreatment.

\section{INTRODUCTION}

Sugarcane is well known for the production of ethanol and sugar, and it has been the main source of these two products (Choi et al., 2012; Vancov et al., 2012; Zhang et al., 2013). Sugarcane is milled to extract a sugar solution, which can be refined yielding several commercial grades of sugars or can be used to produce ethanol through a fermentation process. Sugarcane bagasse is an industrial waste of this milling process and accounts for approximately $25 \%$ of the sugarcane mass.

Sugarcane bagasse is constituted mainly of cellulose, which can be used to produce "second generation" ethanol (Jafari et al., 2011). Cellulose cannot be directly converted to ethanol and it must be processedfirst to glucose or other sugars, which can be fermented like traditional "first generation" ethanol. Usually, enzymatic hydrolysis is used to convert cellulose to glucose (Zhao et al., 2011).

The bagasse has a complex structure and, besides cellulose, it contains other lignocellulosic materials that impose a more difficult processing task if high yields of sugars and less waste materials are desired.To process the lignocellulosic materials pretreatments can be applied to break the structure of the lignocellulosic matrix, reducing the amount of lignin and hemicellulose, and to modify the crystalline structure of cellulose, making it more susceptible to an enzymatic attack (Sun and Cheng, 2002; Sousa et al., 2009; Luo et al., 2010). The right choice of

\footnotetext{
* To whom correspondence should be addressed
} 
pretreatment can also convert hemicellulose into xylose (Boussarsar et al., 2009).

Several pretreatments have been proposed by several research groups. Among the pretreatments, the acidic, alkaline, peroxide and steam explosion pretreatments are the most applied ones (Chang and Holtzapple, 2000; Sun and Cheng, 2002; Schell et al., 2003; Ohgren et al., 2006; Boussarsar et al., 2009; Sousa et al., 2009; Luo et $a l ., 2010)$. Until now, no pretreatment has been considered the best process option and the reports show that the best pretreatment may depend on the composition and structural characteristics of the material.

In this work, we explore the use of acidic followed by alkaline pretreatment and the peroxide pretreatment on sugarcane bagasse originated from sugarcane produced in the Northeast of Brazil, which has different characteristics than the most common sugarcane produced in the Southeast of Brazil. The Northeastern variety has a lower amount of cellulose (39\%) and lignin (17\%), a higher amount of hemicellulose $(28 \%)$ and ashes $(8 \%)$ than the Southeaster variety $(50-45 \%, 30-22 \%, 22-27 \%$ and $3-4 \%$ respectively) (Canilha et al., 2011; Maitan-Alfenas et al., 2015; Rocha et al., 2015).

The aim of the acidic pretreatment is to solubilize part of the hemicellulose, exposing a larger area of cellulose to the enzymatic attack (Schell et al., 2003). The alkaline pretreatment is applied to remove part of the lignin and to reduce the degree of crystallinityof cellulose (Chang and Holtzapple, 2000), while the peroxide pretreatment aims to increase the efficiency of the enzymatic hydrolysis by oxidative delignification and by reducing the degree of crystallinity of cellulose (Ohgren et al., 2006; Boussarsar et al., 2009).

The influence of the pretreatments on the structure of the biomass can be verified using scanning electron microscopy (SEM) methodology (Xu et al., 2006; Brigida et al., 2010; Reiner, 2010; Zhao et al., 2010), which was also applied in this work. A study (Riyajan and Intharit, 2011) on the morphology of sugarcane bagasse subjected to a combined sodium hydroxide and silane pretreatment showed that the surface of raw bagasse exhibited lower roughness when compared with the pretreated bagasse, which was caused by the removal of fatty acids from the surface of the bagasse.

Enzymatic hydrolysis to convert cellulose and hemicellulose to fermentable sugars has been studied extensively (Galbe and Zacchi, 2002; Han and Chen, 2008; Zhou et al., 2009; Yang et al., 2011). The conclusion of most researches shows that at least three enzymes are required to obtain glucose from cellulose by enzymatic hydrolysis. Endoglucanases (EG) (EC 3.2.1.4) hydrolyzecellulose and produce oligomers; cellobiohydrolases or exoglucanases (CBH) (EC3.2.1.91) convert the oligomers into cellobiose and soluble cellodextins. Further, $\beta$-glucosidases (BG) orcellobiases(EC 3.2.1.21) convert cellobiose and cellodextrinsto glucose (Zhou et al., 2009).There is still not a general optimal process for the enzymatic hydrolysis process and an optimization for different biomass and pretreatments is required, because the process will also depend on the composition and structural characteristics of the material.

The objective of this work was to studyand to optimize the enzymatic hydrolysis of the sugarcane bagasseproduced in the Northeast of Brazil subjected to two different pretreatments, aiming at enhancement of the production of glucose and xylose.

\section{MATERIALS AND METHODS}

\section{Materials}

The sugarcane bagasse used in this work was provided by Usina Estivas (Arês - RN, Brazil) and was originated by sugarcane produced in the Northeast of Brazil. The bagasse was collected after grinding and contained $50 \%$ of humidity and $2 \%$ of reducing sugars $(\mathrm{w} / \mathrm{w})$. The bagasse was washed and then milled prior to use and only particles less than $0.29 \mathrm{~mm}$ in diameter were used in this study.

The enzymes used in this work were donated by Novozymes (Bagsvaerd, Denmark) and consisted of the commercial complex NS22074, NS50010, NS50012 and NS22036. The complexes had the following characteristics: NS22074 - cellulase complex with $30 \mathrm{FPU} / \mathrm{mL}$ (476 FPU/g or $295 \mathrm{mg}$ protein/g);NS50010 - $\beta$-glucosidase with 1236 $\mathrm{CBU} / \mathrm{mL}$ (13568 CBU/g or $2714 \mathrm{mg}$ protein/g); NS50012 - enzyme complex with arabinase, $\beta$-glucanase, cellulases, hemicellulases, pectinase and xylanase with160 FXU/mL (3204 FXU/g), $100 \mathrm{FBG} / \mathrm{g}$ and $13700 \mathrm{PGU} / \mathrm{g}$ (or $52 \mathrm{mg}$ protein/g); NS22036 - xylanasewith $600 \mathrm{FXU} / \mathrm{mL}(2000$ $\mathrm{FXU} / \mathrm{g}$ or $2.5 \mathrm{mg}$ protein $/ \mathrm{g}$ ).

\section{Pretreatments}

The combined acid and alkaline pretreatment was carried out in two steps. The first step of the pretreatment was carried out using $20 \%(\mathrm{w} / \mathrm{v})$ of bagasse immersed in a $2 \%(\mathrm{v} / \mathrm{v})$ or $3.66 \%(\mathrm{w} / \mathrm{w})$ sulfuric acid solution. The mixture was subject to heating at $121^{\circ} \mathrm{C}$ for $30 \mathrm{~min}$ (Guo et al., 2009). The resulting solid fraction was washed until $\mathrm{pH}$ 7.0and was used in the second step.

The second step was carried out using $20 \%(\mathrm{w} / \mathrm{v})$ of bagasse immersed ina $4 \%(\mathrm{w} / \mathrm{w})$ sodium hydroxide solution. The mixture was also subjected to heating at $121^{\circ} \mathrm{C}$ for $30 \mathrm{~min}$ (Vasquez et al., 2007). After this period, the $\mathrm{pH}$ of the mixture was adjusted to 7.0 using $\mathrm{HCl}$. The pretreated biomass was washed andstoredat $4{ }^{\circ} \mathrm{C}$ prior to use. This second step was used to enhance the removal of lignin, which is not satisfactorily achieved using solely the acid pretreatment (Chang and Holtzapple, 2000).

The hydrogen peroxide pretreatment was carried out using $4 \%(\mathrm{w} / \mathrm{v})$ of biomass immersed in a $7.35 \%(\mathrm{v} / \mathrm{v})$ or 
$8.15 \%(\mathrm{w} / \mathrm{w})$ hydrogen peroxide solution. The mixture was stirred using a mechanical stirrer (Tecnal model TE-139, Piracicaba/Brazil) at $100 \mathrm{rpm}$ for 1 hat room temperature (Smith, 2011). The resulting solid fraction was washed andstored at $4^{\circ} \mathrm{C}$, prior to use.

The pretreatment process with hydrogen peroxide in alkaline medium was applied to compare with the combined acid and alkaline pretreatment aiming to reduce the number of steps, the amount of waste and inhibitory compounds that may affect the enzymatic hydrolysis (Rabelo et al., 2011) and evaluate the enzymatic hydrolysis with higher hemicellulose content in the pretreated bagasse.The solid fractionafter thepretreatments was calculated based on Equation 1.

$$
\text { Solid fraction }=\frac{\text { Solid part re covered }(g)}{\text { Initial quantity of raw material }(g)}
$$

\section{Enzymatic hydrolysis}

A $2^{2}$ central composite design with three central points was carried out to evaluate the enzymatic activity of the cellulase complex andof the $\beta$-glucosidase. This experimental design aimed at a decrease in the concentration of enzyme used in this kind of enzymatic process, taking as base the NREL digestibility protocol of lignocellulosic biomasssubjected to pretreatments (Selig et al., 2008), which is known to use a very high amount of enzyme. To set this goal, the levels for this design were chosen after a review of the literature where the most satisfactory results were considered as the central point for the design (Ferreira et al., 2009; Rocha et al., 2009; Lu et al., 2010).

The experimental assayswere carried out in Erlenmeyers of $250 \mathrm{~mL}$ placed in a shaker (Tecnal model TE-421, Piracicaba/Brazil) set at $150 \mathrm{rpm}$ and $50^{\circ} \mathrm{C}$. A reaction volume of $20 \mathrm{~mL}$ containing $50 \mathrm{mM}$ citrate buffer at $\mathrm{pH} 4.8$ was used.

The assays were carried out with the bagasse subjected to the combined acid and alkaline pretreatment. An amount of $0.15 \%(\mathrm{w} / \mathrm{w})$ of bagasse, representing $0.1 \%(\mathrm{w} / \mathrm{w})$ of cellulose, was added to the Erlemeyers. The amount of the cellulase complex added to the mixtureranged from 6 to 34 FPU/g cellulose and the amount of $\beta$-glucosidase ranged from 4 to $11 \mathrm{CBU} / \mathrm{g}$ cellulose, following the experimental design.

A $1 \%(\mathrm{w} / \mathrm{w})$ sodium azide solution was added to the mixture in a volume ratio of 1:100 to prevent microorganism growth. Samples were collected to quantify the amount of glucose and to calculate the yield of the process. Statistica v7 was used to design and to analyze the experiments.

\section{Kinetic study}

A 2L bioreactor was used for the kinetic study. The bioreactor (Applikon Dependable Instruments, Netherlands) was equipped with stirring, $\mathrm{pH}$, level, nutrient control and temperature control.The assays were carried out with $1 \mathrm{~L}$ reaction volume, $50 \mathrm{mM}$ citrate buffer, $\mathrm{pH} 4.8$, $1 \%(\mathrm{w} / \mathrm{w})$ sodium azide, $50^{\circ} \mathrm{C}$ and stirring set at $200 \mathrm{rpm}$. This bioreactor was chosen because it is the appropriate equipment for a future enzymatic hydrolysis scale-up and SSF process study.

The initial amount of biomass was set at $6 \%(\mathrm{w} / \mathrm{w})$ of cellulose, which corresponds to $9.25 \%$ of bagasse $(\mathrm{w} / \mathrm{w}$ ) according to literature (Ruiz et al., 2008) and previous results. This amount of biomass was chosen aiming at maximal production of glucose, and to avoid problems with mass transfer effects. Samples were collected to quantify glucose and xylose to calculate the yield (conversion) of the process.

The enzymatic hydrolysis assays were done usingthe cellulases complex and $\beta$-glucosidase with the combined acid and alkaline pretreated bagasse and the hydrogen peroxide pretreated bagasse.

An assaywas also carried out with the same conditions used to hydrolyze the hydrogen peroxide pretreated bagasse, but with the addition of two enzyme kits: $0.4 \%$ $(\mathrm{v} / \mathrm{v})$ of enzyme complex (NS50012) and $0.25 \%(\mathrm{v} / \mathrm{v})$ of xylanase (NS22036). The main goal of this study was to induce an effective enzymatic attack onthe hemicellulose contained in the pretreated bagasse, increasing the surface area of cellulose,allowing enhanced enzymatic attack as well as releasingxylose in the medium.

Equation 2 presents how the global yield of sugars was determined after the entire process (pretreatment and enzymatic hydrolysis).

$$
\text { Yield }(\%)=\text { Solid fraction } \cdot \frac{\text { Produced } \operatorname{sugar}(g)}{\text { Initial amount of raw material }(g)} \cdot F_{C} \cdot 100
$$


where $\mathrm{F}_{\mathrm{C}}$ is the correction factor due to the weight gain caused by the hydrolysis of the hydroglucose monomer. $\mathrm{F}_{\mathrm{C}}$ was assumed to be $162 / 180$, which is the ratio of the molecular weights of anhydroglucan (present in the cellulose chain) and glucose (formed upon hydrolysis).

\section{Sugarcane bagasse characterization}

The amount of cellulose, hemicellulose, lignin and ash were obtained according to the methods described by Gouveia et al.(2009). The compositional characterization was carried out with the solid fraction that was the object of this study.

The quantification of organic solvent and hot water extractives was carried out according to the NREL procedure (National Renewable Energy Laboratory, Golden, USA) (Sluiter et al., 2008) with modifications, hot water extractives quantification was carried out by HPLC. Sugar content was quantified in the untreated and pretreated bagasses. Acetic acid, formic acid, HMF and furfural content were determined only for the pretreated bagasse. All characterizations were assayed in triplicate.

Scanning electron microscopy (SEM) was used to observe the morphology of the untreated and pretreated bagasse (Phillips XL-30 ESEM, USA). SEM was carried out using an acceleration voltage of $20 \mathrm{kV}$ and working distance of $10 \mathrm{~mm}$, spot size of 4.0, SE detector and metallizer (SCD-Bal-Tec 005, USA). The aim of this analysis was to study the changes on the external structure caused by the pretreatments.

FTIR analysis was used to detect the presence of the mains organic groups that constitutes the lignocellulosic structure. FTIR analysis was carried out in the range of 400 to $4000 \mathrm{~cm}^{-1}$ using a Fourier Transform infrared spectrophotometer (Bio-Rad Excalibur Series model FTS $3000 \mathrm{MX}$, USA) and $\mathrm{KBr}$ as dispersant. Thus, it was possible to detect the changes caused by the pretreatments in relation to the content of lignin and hemicellulose.

\section{Analytical procedures}

After hydrolysis, the samples were subjected to $100^{\circ} \mathrm{C}$ for $10 \mathrm{~min}$ aiming at enzyme inactivation (Benko et al., 2008). The samples were centrifuged at $14000 \mathrm{rpm}$ (18406.7 $\times g$ ) (Eppendormodel 5424, Germany) for 30 min, filtered in PES (Polyethersulfone) membrane of 0.22 $\mu \mathrm{m}$ (TPP, Switzerland) and then stored at $-20^{\circ} \mathrm{C}$.
The amount of sugars, HMF, furfural, organics acids wasobtained by HPLC using a Shim-pack SCR 101$\mathrm{H}$ column (SHIMADZU, Kyoto/Japan) at $65^{\circ} \mathrm{C}$, with 5 $\mathrm{mM}$ sulfuric acid in MiliQ water (Barnstead EasyPure RF System model D7031, Iowa/EUA) as eluent, flow rate of $0.6 \mathrm{~mL} / \mathrm{min}$ and refractive indexdetector (SHIMADZU model RID-10A, Japan).

The amount of digested cellulose (conversion of cellulose into glucose) was determined in an indirect form according to the digestibility protocol of lignocellulosic biomass subjected to pretreatments (Selig et al., 2008).The enzymatic activities were determined byGhose (1987).

\section{RESULTS AND DISCUSSION}

\section{Acidic followed by alkaline pretreatment}

Table 1 presents the composition of the untreatedbagasse and the bagasse pretreated with the acidic followed by alkaline pretreatment. This combined pretreatment increased the amount of cellulose by $68.3 \%$ and reduced the amount of hemicellulose by $63.2 \%$. The reduction of hemicellulose observed in the combined acid and alkaline pretreated bagasse can be attributed to acid attack promoted by the pretreatment (Schell et al., 2003).

The amount of lignin in the pretreated biomass was reduced by $55.9 \%$. This reduction was probably caused by the alkaline pretreatment, which is known to increase the contact area in the cellulose matrix resulting in a lower adsorption of lignin by the enzyme(Chang and Holtzapple, 2000).

The results obtained with this variety of sugarcane bagasse and including the alkaline pretreatment were better than those reported by Canilha et al.(2011); who applied only the acidic pretreatment. In their research, they obtained $59.3 \%$ of cellulose, $3.7 \%$ of hemicellulose and $33.8 \%$ of lignin after acid pretreatment $\left(150{ }^{\circ} \mathrm{C}\right.$ for 30 minutes and $2.5 \% \mathrm{v} / \mathrm{v}$ of sulfuric acid solution) of a raw material (sugarcane bagasse) with $45.0 \%$ of cellulose, $25.8 \%$ of hemicellulose and $19.1 \%$ of lignin.

The pretreated bagasse presented a low amount of organic solvent extractives, but the hot water extractives increased. This behavior could be explained by the production of monomeric residues during the pretreatment, which stay adsorbed in the lignocellulosic matrix,and are removed only in boiling water.

Table 1. Composition of the pretreated and the untreated bagasse.

\begin{tabular}{|c|c|c|c|c|c|c|}
\hline Pretreatment & $\begin{array}{l}\text { Cellulose } \\
(\mathrm{w} / \mathrm{w} \%)\end{array}$ & $\begin{array}{l}\text { Hemicellulose } \\
\text { (w/w \%) }\end{array}$ & $\begin{array}{l}\text { Total lignin } \\
\text { (w/w \%) }\end{array}$ & $\begin{array}{l}\text { Organic solvent } \\
\text { extractives } \\
(w / w \%)\end{array}$ & $\begin{array}{l}\text { Hot water } \\
\text { extractives } \\
(\mathrm{w} / \mathrm{w} \%)\end{array}$ & $\begin{array}{c}\text { Ash } \\
(\mathrm{w} / \mathrm{w} \%)\end{array}$ \\
\hline Untreated & $38.59 \pm 3.45$ & $27.89 \pm 2.68$ & $17.79 \pm 0.62$ & $1.61 \pm 0.16$ & $1.11 \pm 1.23$ & $8.80 \pm 0.02$ \\
\hline acid and alkaline & $64.89 \pm 1.57$ & $9.61 \pm 0.94$ & $7.85 \pm 0.24$ & $0.71 \pm 0.04$ & $11.23 \pm 0.53$ & $5.75 \pm 0.14$ \\
\hline hydrogen peroxide & $51.85 \pm 4.56$ & $23.02 \pm 4.23$ & $9.02 \pm 0.24$ & $0.44 \pm 0.03$ & $11.25 \pm 0.95$ & $5.30 \pm 0.07$ \\
\hline
\end{tabular}


The solid fraction obtained after the pretreatment was $0.26 \mathrm{~g} / \mathrm{g}$ raw material. Considering only the solid matter (dry basis), $48 \%$ of the solids had been solubilized in the liquid fraction of the reaction.

SEM and FTIR analysis were carried out to study the structural modification of the pretreated bagasse. Figure 1 presents the results of the morphological study carried out by SEM (1000× magnification). Differences in morphology could be noticed in the bagasse after the pretreatment and after the enzymatic hydrolysis. Figure 1A shows the raw bagasse where some parallel cracks can be observed and that are common to sugarcane bagasse. The number of parallel cracks increased and perpendicular cracks appeared after the combined acid and alkaline pretreatment (Figure 1B). A significant structural change occurred with the pretreated bagasse after hydrolysis (Figure 1C), which presented muchsuperficial breakdown of the structure.

Figure 2 presents the results of the FTIR assays for the untreated and for the pretreated bagasse and Table 2 presents the organic groups for the bands that were observed.Similar trends in the bands at $2910 \mathrm{e} 2850 \mathrm{~cm}^{-1}$ were observed in all assays. Changes were not observed in the 1050,1100 e 1150 $\mathrm{cm}^{-1}$ bands (ether and ester linkages) for the combined acid and alkaline pretreated in relation to the untreated bagasse.

\section{Peroxide pretreatment}

Table 1 presents the composition of the pretreated bagasse. The peroxide pretreatment increased the amount of cellulose by $34.4 \%$ and reduced the amount of hemicellulose by $17.5 \%$. The peroxide pretreatment showed a lower efficiency, in comparison with the acidic followed by the alkaline pretreatment, because the conversion into easier-to-hydrolyze molecules was lower.The amount of lignin was reduced by $49.3 \%$, which was lower than the reduction observed for the acidicfollowed by the alkaline pretreatment.An interesting point regarding this pretreated bagasse is that it can be converted further on into xylose due to its high hemicellulose content (Boussarsar et al., 2009).

The peroxide pretreatment resulted in the reduction of organic solvent extractives and in the increase inhot water extractives, similar to the results observed for the acidic followed by alkaline pretreatment. The reduction in organic solvent extractives observed for this variety of bagasse was similar to the data already reported in the literature (Alvira et al., 2009).

The solid fraction obtained after the pretreatmentwas $0.21 \mathrm{~g} / \mathrm{g}$ raw material, which was $19 \%$ lower than the result obtained by the acidic followed by the alkaline pretreatment. The peroxide pretreatment produceda higher amount of soluble molecules, with $58 \%$ of the solid matter being solubilized in the reaction medium. The hydrogen peroxide pretreatment also produced a considerable amount of foam during reaction, which increased the loss of solid matter.
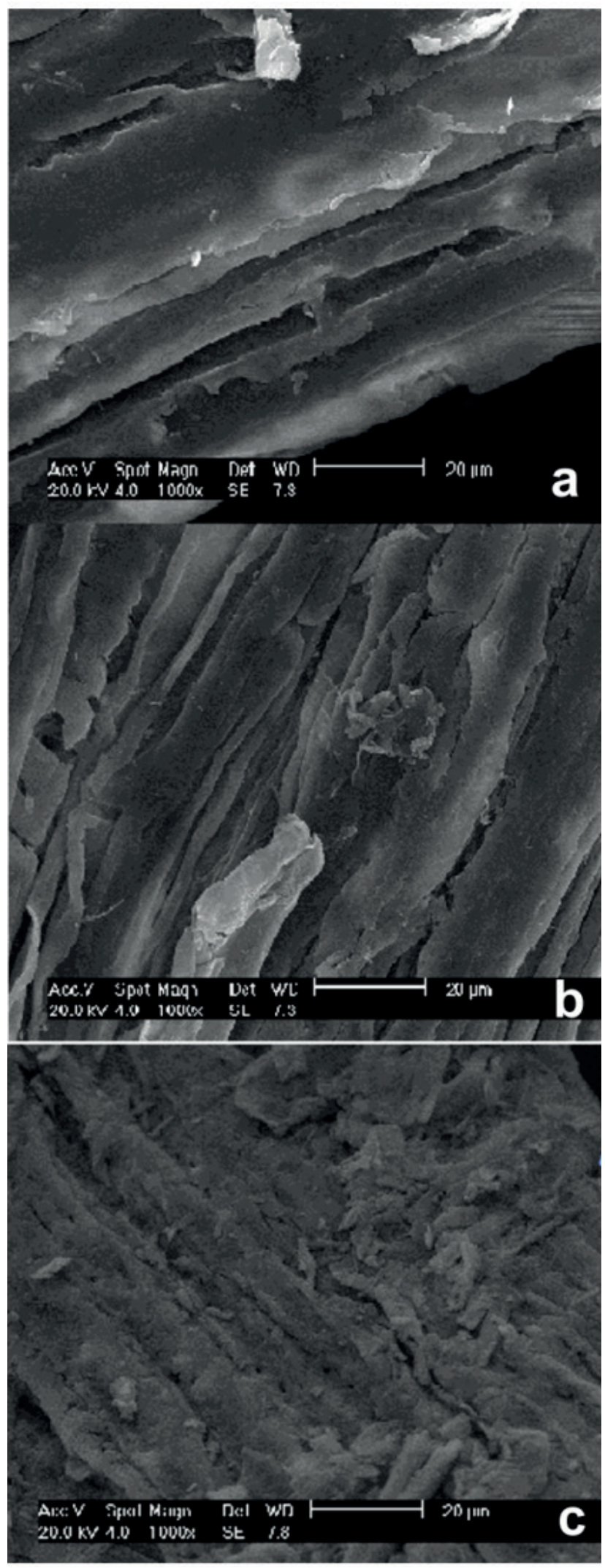

Figure 1. Morphology of the untreatedbagasse (a), the bagasse subjected to the combined acid and alkaline pretreatment (b), and latter bagasse after hydrolysis (c). 
Table 2. Organic groups found in the untreated and in the solid part of the pretreated bagasse (Pan, 2008; Guo et al., 2009).

\begin{tabular}{cc}
\hline $\begin{array}{c}\text { Wavenumber } \\
\left(\mathrm{cm}^{-1}\right)\end{array}$ & Organic group \\
\hline 3400 & $\mathrm{O}-\mathrm{H}$ \\
2910 & $\mathrm{C}-\mathrm{H}$ \\
2850 & $\mathrm{OCH}$ \\
2350 & - \\
2340 & - \\
1250 & $\mathrm{C}-\mathrm{C}$ \\
1150 & O-C $=\mathrm{O}$ \\
1100 & O-C $=\mathrm{O}$ \\
1050 & $\mathrm{C}-\mathrm{O}-\mathrm{C}$ \\
900 & $\beta$-glucosidic linkage \\
& between sugars \\
\hline
\end{tabular}

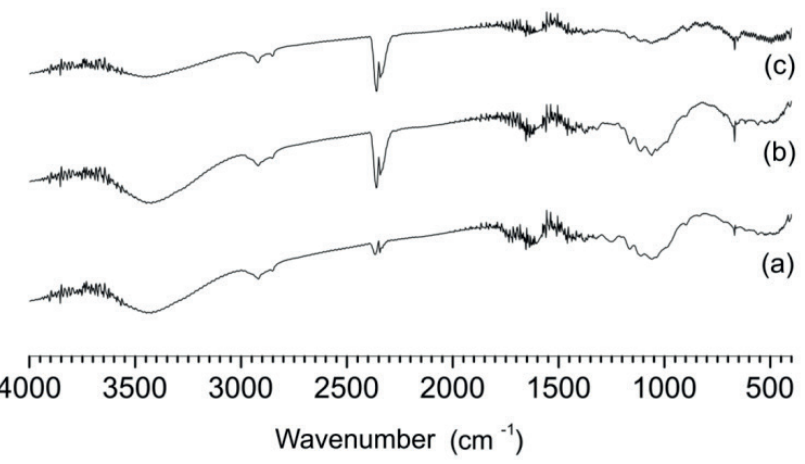

Figure 2. FTIR spectra of the raw biomass (a); and the bagasse treated with the combined acid and alkaline pretreatment (b) and with the hydrogen peroxide pretreatment (c).

Figure 3 presents the results of the morphological study for the bagasse pretreated by the hydrogen peroxide process(1000× magnification). A larger number of parallel and perpendicular cracks appeared in the pretreated bagasse in comparison to the other pretreatment (Figure 3A). After hydrolysis, the hydrogen peroxide pretreatment influenced a more significant change in the bagasse, where both superficial and internal breakdown of the structure were observed (Figure 3B). Thus, the peroxide pretreatment was more efficient in terms of providing an extended degree of structural damage in this biomass.

The results obtained by FTIR assays showed a lower intensity of the bands, indicating a higher degree of change in the lignin bonded to hemicellulose (Figure 2). No peaks were observed between 1375 e $1325 \mathrm{~cm}^{-1}$, which represents hydroxyl phenolic groups (Guo et al., 2009). The absence of these peaks rule out the presence of phenolic hydroxyl groups, which present an inhibitory effect on cellulases (Pan, 2008).

\section{Enzymatic hydrolysis}

The enzymatic hydrolysis was carried out and the yieldsof fermentable sugars are presented in Figure 4.

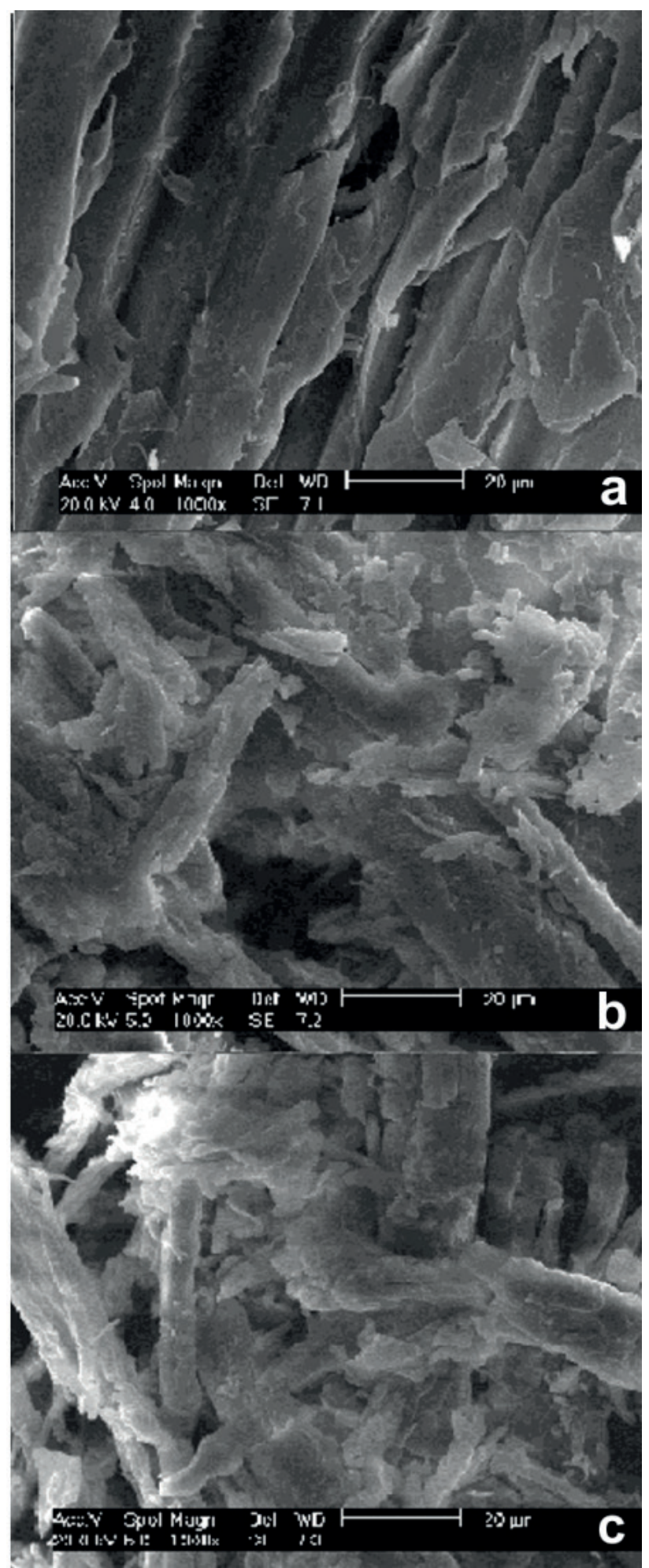

Figure 3. Morphology of the bagasse subjected to thehydrogen peroxide pretreatment (a), and the latter bagasse after hydrolysis with the enzymatic complexes NS22074 and NS50010 (b), and the bagasse after hydrolysis with the enzymatic complexes NS22074, NS50010, NS50012 and NS22036 (c)

The concentration of cellulase plays a major role in the enzymatic hydrolysis, since the yield increased with 


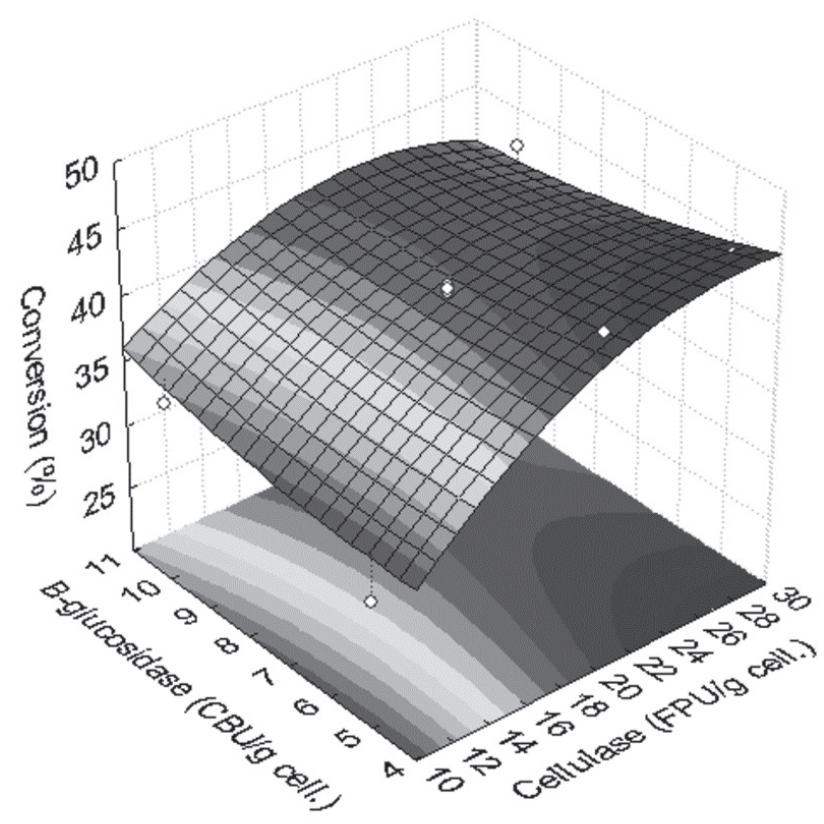

Figure 4. Conversion of cellulose as a function of cellulase and $\beta$-glucosidase activities.

increasing cellulase concentration. Although the increase in cellulase concentration increased the yield, an inhibition or deactivation of cellulase was observed because the increase in yield was not proportional to the increase in cellulase content and an asymptotic tendency was observed at high cellulase concentration.

The pretreatment of sugarcane bagasse usually originates phenolic compounds from lignin and these compounds are in part responsible for the inhibition of cellulase (Ximenes et al., 2010). Another contributing factor for the inhibited yield is the production of xylose, which is significantly more inhibitory to glucan hydrolysis and thus to the global yield of the process (Kumar and Wyman, 2009; Ximenes et al., 2010).

The increase in the concentration of $\beta$-glucosidase increased the yield when low cellulase concentration $(<15$ FPU/g) was applied, but decreased the yield of fermentable sugars when high cellulase concentration $(>25 \mathrm{FPU} / \mathrm{g}$ ) was applied.

This result may be related to the deactivation of cellulase and $\beta$-glucosidase caused by phenols, which are known inhibitors and deactivators of these enzymes. The inhibitory effect of phenolic compounds occurs to a greater extent in $\beta$-glucosidase than in cellulose (Ximenes et al., 2011)prior to the respective enzyme assays. Tannic, gallic, hydroxy-cinnamic, and 4-hydroxybenzoic acids, together with vanillin caused $20-80 \%$ deactivation of cellulases and/or $\backslash u 03 b 2$-glucosidases after 24 . h of preincubation while enzymes pre-incubated in buffer alone retained all of their activity. The strength of the inhibition or deactivation effect depended on the type of enzyme, the microorganism from which the enzyme was derived, and the type of phenolic compounds present. lu03b2Glucosidase from Aspergillus niger was the most resistant to inhibition and deactivation, requiring about 5 and 10fold higher concentrations, respectively, for the same levels of inhibition or deactivation as observed for enzymes from Trichoderma reesei. Of the phenol molecules tested, tannic acid was the single, most damaging aromatic compound that caused both deactivation and reversible loss (inhibition. The decrease in the global yield could be explained by this inhibitory response when high cellulase and high $\beta$-glucosidase concentrations were applied in the hydrolysis.

The $\mathrm{R}^{2}$ values for the experimental design were higher than 0.98 , thus satisfactory for modeling proposes and for defining an optimal operating condition. The highest yield obtained in the enzymatic hydrolysis was $41 \%$, which was obtained using $27 \mathrm{FPU} / \mathrm{g}$ cellulose of cellulase and 4 $\mathrm{CBU} / \mathrm{g}$ cellulose of $\beta$-glucosidase.

This optimal operating condition is close to the operating conditions presented in the literature for bagasse produced from other sugarcane varieties (Han and Chen, 2008; Ferreira et al., 2009; Lu et al., 2010; Zhao et al., 2011).Thus, for practical application during optimization, the optimal condition for one sugarcane variety can be used as center point to start an experimental design for other varieties and the factors can be set within a $20 \%$ deviation from the center point.

\section{Dynamics of the enzymatic hydrolysis}

The bioreactor assays were carried out by applying the optimal operating conditions obtained from the experimental designs $(6 \% \mathrm{w} / \mathrm{w}$ of cellulose, 27 FPU/g cellulose of cellulase and $4 \mathrm{CBU} / \mathrm{g}$ cellulose of $\beta$-glucosidase) and with the same experimental conditions plus the addition of hemicellulases and xylanases as described in the materials and methods section, given the high amount of hemicellulose in bagasse.

Figure 5 presents the conversion and glucose concentration for the assays carried out with the combined acid and alkaline pretreated bagasse. The addition of hemicellulases and xylanases increased the overall yield of the process and the concentration of glucose. The use of xylanases in the combined acid and alkaline pretreated bagasse was not successful and the concentration of xylose was low $(3.9 \mathrm{~g} / \mathrm{L})$ after $72 \mathrm{~h}$ of reaction.

The concentration of compounds that may inhibit the reaction $(0.17 \mathrm{~g} / \mathrm{L}$ of acetic acid, $0.11 \mathrm{~g} / \mathrm{L}$ of HMF and $0.04 \mathrm{~g} / \mathrm{L}$ of furfural) remained constant during the course of reaction and may not be responsible for the differences observed in the yield.

Figure 6 presents the results of the enzymatic hydrolysis carried out using the hydrogen peroxide pretreatment. The concentrations of glucose, after enzymatic hydrolysis, were $33.4 \mathrm{~g} / \mathrm{L}$ and $38.2 \mathrm{~g} / \mathrm{L}$, respectively, for the assay 

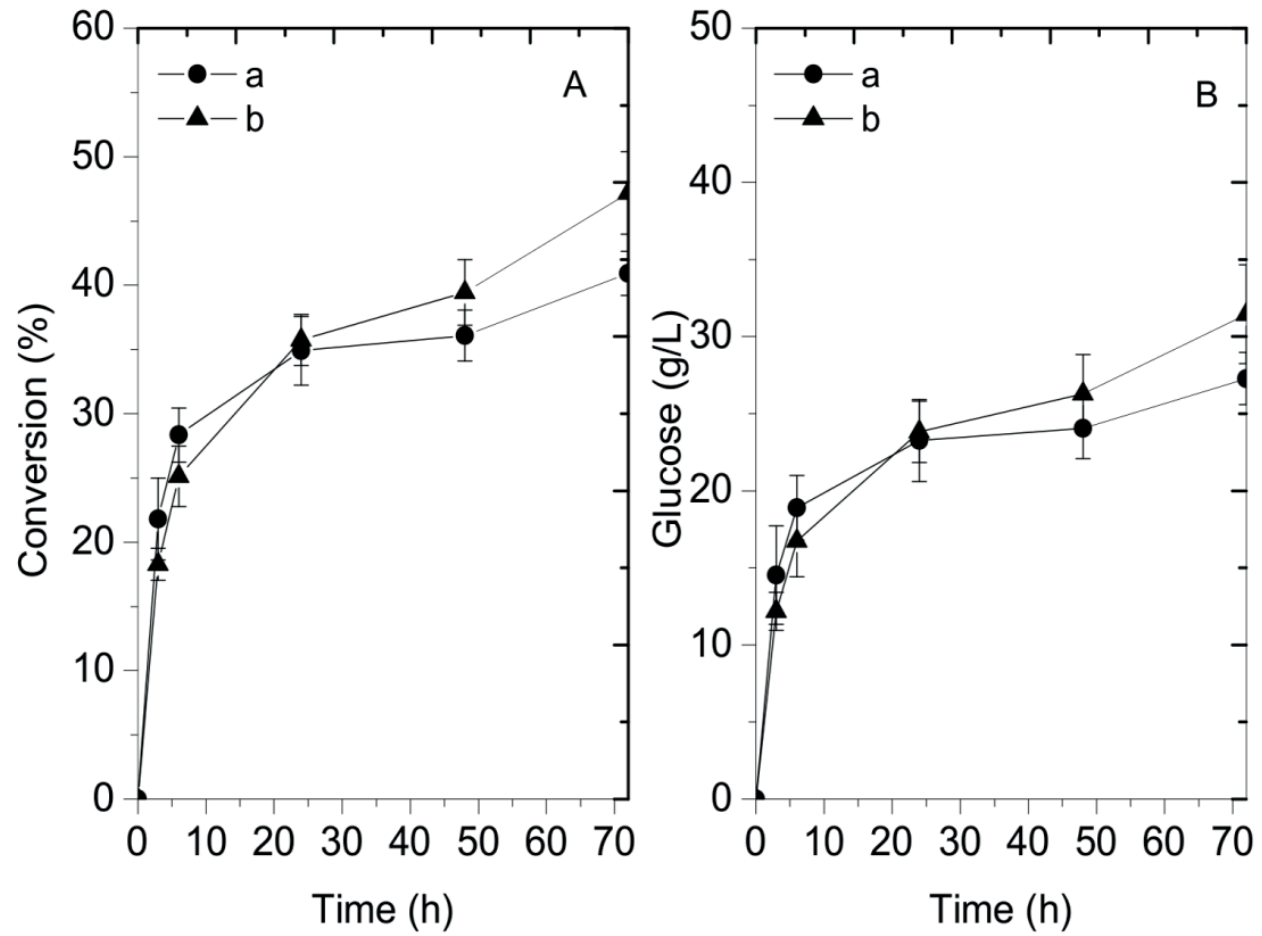

Figure 5. Conversion and glucose concentration throughout the enzymatic hydrolysis with the acid and alkaline pretreated bagasse. (a) hydrolysis using the enzymatic complexes NS22074 and NS50010;(b)hydrolysis using the enzymatic complexes NS22074, NS50010, NS50012 and NS22036.
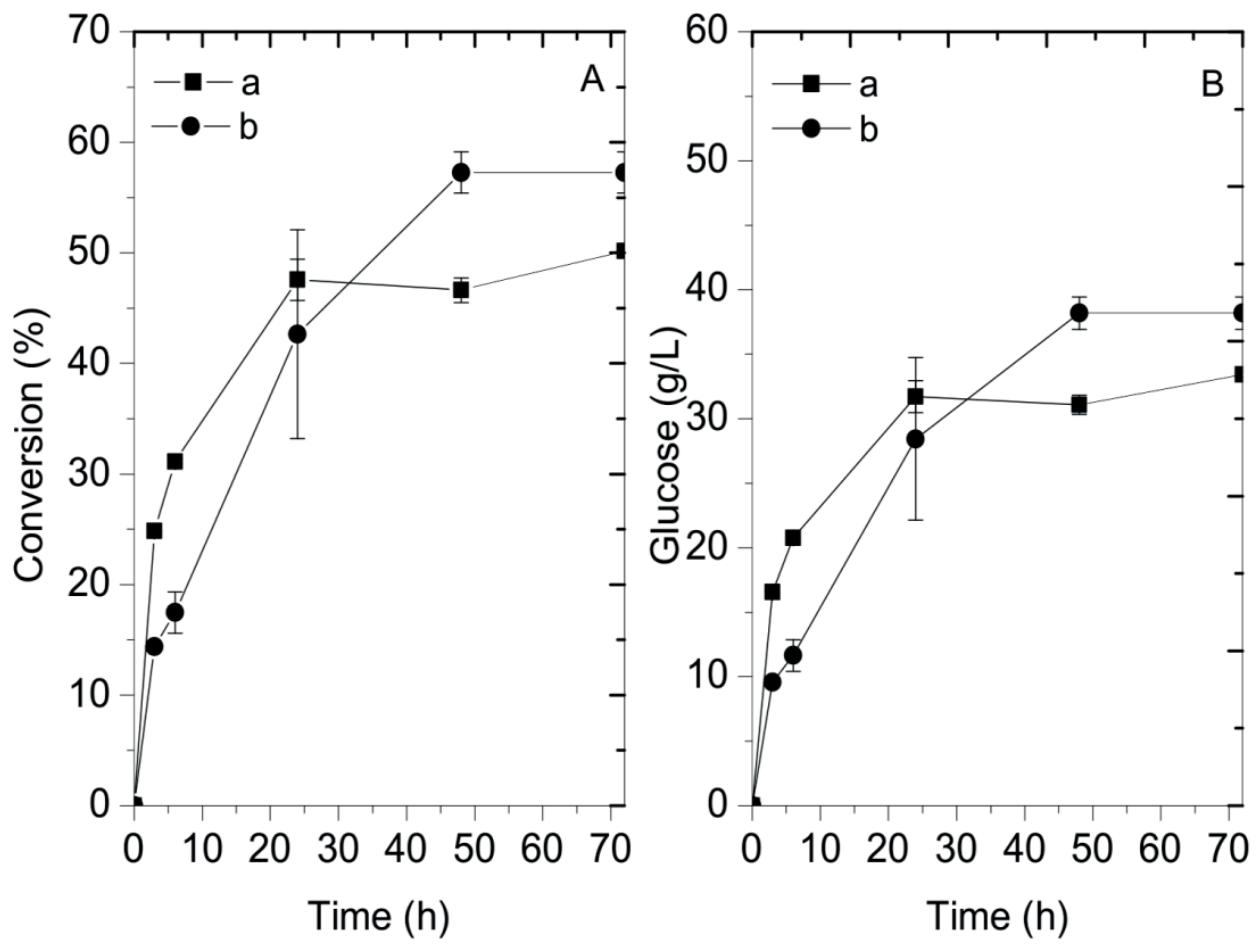

Figure 6. Conversion and glucose concentration throughout the enzymatic hydrolysis with the bagasse pretreated with hydrogen peroxide. (a) hydrolysis using the enzymatic complexes NS22074 and NS50010;(b) hydrolysis using the enzymatic complexes NS22074, NS50010, NS50012 and NS22036. 
employing cellulases and $\beta$-glucosidase and for the assay using cellulases, $\beta$-glucosidase, hemicellulasesand xylanases. These values represent, respectively, 50.2\% and $57.3 \%$ of the theoretical conversion of celluloseinto glucosethat could be achieved.

The hydrogen peroxide pretreatment produced a bagasse that was very prone to the production of xylose. The xylose concentrations in both processes were equal to $17.7 \mathrm{~g} / \mathrm{L}$ ( $89.7 \%$ of the theoretical conversion to xylose). As such, the addition of xylanases into the enzymatic mixture is not required when the bagasse is pretreated with hydrogen peroxide.

The hydrogen peroxide pretreatment showed a higher reduction in the amount of compounds that can be extracted by organic solvents than the combined acid and alkaline pretreatment. The increases in hot water extractants in both pretreatments were statistically similar. Thus, it is likely that more inhibitors may have been washed off during the hydrogen peroxide pretreatment than during the combined acid and alkaline pretreatment. This observation is also supported by the FTIR analysis, which showed smaller peaks of phenolic-related compounds in the bagasse subjected to the hydrogen peroxide pretreatment. The lower amount of phenolic inhibitors in thebagasse subjected to the hydrogen peroxide pretreatment may have contributed to the better performance of the enzymatic hydrolysis with this pretreated bagasse.

The inhibitors $(0.2 \mathrm{~g} / \mathrm{L}$ of acetic acid, $0.1 \mathrm{~g} / \mathrm{L}$ of $\mathrm{HMF}$ and $0.03 \mathrm{~g} / \mathrm{L}$ of furfural) did not increase significantly during the reaction, thus not being able to impart any significant inhibition of the hydrolysis process.

Comparing both pretreatments, the hydrogen peroxide pretreatment was more successful in helping the hydrolysis process. The production of glucose was $26 \%$ higher and the production of xylose was 3.7 times higher than the production attained using the acid followed by alkali pretreatment.

The yields obtained using the process described herein were higher than the results reported for the enzymatic hydrolysis after steam explosion pretreatment at temperatures of $200^{\circ} \mathrm{C}$ or below (Ruiz et al., 2008), after ozone pretreatment (Pereira et al., 2016) and after alkali pretreatment (Pereira et al., 2016) (comparisons done with the optimal condition). However, the yields were on average $35 \%$ lower than the pretreatment at temperatures above $200{ }^{\circ} \mathrm{C}$, and after alkali pretreatment with the addition of high amounts $(8 \% \mathrm{w} / \mathrm{w})$ of sodium sulfate (Mesquita et al., 2016).

Sugarcane bagasses from the Northeast and from the Southeast of Brazil, pretreated with hydrogen peroxide, showed a different behavior. The southeastern variety, which contains a lower amount of ashes in its composition, resulted in a higher global yield (65\%) after enzymatic hydrolysis using a mixture of cellulase and $\beta$-glucosidase
(Rabelo et al., 2014). The differences among the results reinforce the possibility that the amount of ashes in the sugarcane bagasse may inhibit the enzymatic hydrolysis.

The new combination of different enzymes also increased the conversion of bagasse into sugars, improving the final concentration of glucose and xylose in the fermentation media. The inclusion of NS50012 (enzyme complex with arabinase, $\beta$-glucanase, cellulases, hemicellulases, pectinase and xylanase) in the enzyme mixture increased the amount of glucose and xylose by $12.7 \%$ and $378.4 \%$ when compared to a previous work carried out by our group, considering the enzymatic hydrolysis of the acid followed by alkali pretreated bagasse (Guilherme et al., 2015). The enhanced production of xylose improved the overall concentration of fermentable sugars, especially by the addition of this enzyme complex that contains xylanase. When compared to our previous work (Guilherme et al., 2015), the total concentration of fermentable sugars increased from 37.7 to $55.9 \mathrm{~g} / \mathrm{L}$, a $48.3 \%$ increase.

The addition of moreand different enzymes to the enzymatic hydrolysis complex has an impact on cost, as well as the introduction of the hydrogen peroxide pretreatment into the biochemical process. It is likely that the capital cost to introduce a new processing step will rise. The operational cost will also increase due to the need of more enzymes and reactants. The gain in ethanol productivity in the subsequent fermentative process by almost $50 \%$ may compensate the extra cost, but realistic economic analysis that considers global and regional prices and costs should be done prior to implementation of such technology.

\section{CONCLUSION}

Applying the hydrogen peroxide pretreatment prior to enzymatic hydrolysis increased the amount of total fermentable sugars, especially glucose and xylose, in sugarcane bagasse from the cultivar mainly used in the Brazilian Northeast. Hydrogen peroxide induced significant changes in the structure of the sugarcane bagasse, allowing an enhanced production of xylose.

The addition of NS50012 (enzyme complex that contains xylanase) to the sugarcane bagasse pretreated with acid followed by alkali pretreatment increased the amount of total fermentable sugars, especially xylose, but still at lower concentration when compared to the process that used hydrogen peroxide pretreated bagasse.

\section{ACKNOWLEDGEMENTS}

The authors thank CNPq and CAPES for the financial support; to Novozymes for the donation of the enzymes; and to the Center of Study in Petroleum and Natural Gas for the SEM analysis. 


\section{REFERENCES}

Alvira, P.T.P., Ballesteros, E.M. and Negro, M.J., Pretreatment technologies for an efficient bioethanol production process based on enzymatic hydrolysis: A review. Bioresour. Technol., 101, 4851-4861 (2009).

Benko, Z., Siika-Ahob, M., Viikari, L. and Reczeya, K., Evaluation of the role of xyloglucanase in the enzymatic hydrolysis of lignocellulosic substrates. Enzym. Microbiol. Technol., 43, 109-114 (2008).

Boussarsar, H., Roge, B. and Mathlouthi, M., Optimization of sugarcane bagasse conversion by hydrothermal treatment for the recovery of xylose. Bioresour. Technol., 100, 6537-6542 (2009).

Brigida, A.I.S., Calado, V.M.A., Gonçalves, L.R.B. and Coelho, M.A.Z., Effect of chemical treatments on properties of green coconut fiber. Carbohydr. Polym., 79, 832-838 (2010).

Canilha, L., Santos, V.T.O., Rocha, G.J.M., Silva, J.B.A., Giulietti, M., Silva, S.S., Felipe, M.G.A., Ferraz, A., Milagres, A.M.F. and Carvalho, W., A study on the pretreatment of a sugarcane bagasse sample with dilute sulfuric acid. J. Ind. Microbiol. Biotechnol., 38, 1467-1475 (2011).

Chang, V. and Holtzapple, M., Fundamental factors affecting biomass enzymatic reactivity. Appl. Biochem. Biotechnol., 84-86, 5-37 (2000).

Choi, H.S., Choi, Y.S. and Park, H.C., Fast pyrolysis characteristics of lignocellulosic biomass with varying reaction conditions. Renew. Energy, 42, 131-135 (2012).

Ferreira, S., Duarte, A.P., Ribeiro, M.H.L., Queiroza, J.A. and Domingues, F.C., Response surface optimization of enzymatic hydrolysis of Cistus ladanifer and Cytisus striatus for bioethanol production. Biochem. Eng. J., 45, 192-200 (2009).

Galbe, M. and Zacchi, G., A review of the production of ethanol from softwood. Appl. Microbiol. Biotechnol., 59, 618-628 (2002).

Ghose, T.K., Measurement of cellulose activities. Pure Appl. Chem., 59, 257-268 (1987).

Gouveia, E.R., Nascimento, R.T., Souto-Maior, A.M. and Rocha, G.J.M., Validação de metodologia para a caracterização química de bagaço de cana-de-açúcar. Quim. Nova, 32, 1500-1503 (2009).

Guilherme, A.A., Dantas, P.V.F., Santos, E.S., Fernandes, F.A.N. and Macedo, G.R., Evaluation of composition, characterization and enzymatic hydrolysis of pretreated sugar cane bagasse. Brazilian J. Chem. Eng., 32, 23-33 (2015).

Guo, G.L., Hsu, D.C., Chen, W.H. and Hwang, W.S., Characterization of enzymatic saccharification for acidpretreated lignocellulosic materials with different lignin composition. Enzym. Microbiol. Technol., 45, 80-87 (2009).

Han, Y. and Chen, H., Characterization of $\beta$-glucosidase from corn stover and its application in simultaneous saccharification and fermentation. Bioresour. Technol., 99, 6081-6087 (2008).

Jafari, V., Labafzadeh, S.R., Jeihanipour, A., Karimi, K. and Taherzadeh, M.J., Construction and demolition lignocellulosic wastes to bioethanol. Renew. Energy, 36, 2771-2775 (2011).

Kumar, R. and Wyman, C.E., Effect of supplementation at moderate cellulase loadings on initial glucose and xylose release from corn stover solids pretreated by leading technologies. Biotechnol. Bioeng., 102, 45-67 (2009).

Lu, Y., Wang, Y., Xu, G., Chu, J., Zhuang, Y. and Zhang, S., Influence of High Solid Concentration on Enzymatic Hydrolysis and Fermentation of Steam-Exploded Corn Stover Biomass. Appl. Biochem. Biotechnol., 160, 360-369 (2010).

Luo, L., Voet, E.V.D. and Huppes, G., Biorefining of lignocellulosic feedstock - Technical, economic and environmental considerations. Bioresour. Technol., 101, 5023-5032 (2010).

Maitan-Alfenas, G.P., Visser, E.M., Alfenas, R.F., Nogueira, B.R.G., Campos, G.G., Milagres, A.F., Vries, R.P. and Guimarães, V.M., The influence of pretreatment methods on saccharification of sugarcane bagasse by an enzyme extract from Chrysoporthe cubensis and commercial cocktails: A comparative study. Bioresour. Technol., 192, 670-676 (2015).

Mesquita, J.F., Ferraz, A. and Aguiar, A., Alkaline-sulfite pretreatment and use of surfactants during enzymatic hydrolysis to enhance ethanol production from sugarcane bagasse. Bioprocess Biosyst. Eng., 39, 411-448 (2016).

Ohgren, K., Bengtsson, O., Gorwa-Grauslund, M.F., Galbe, M., Hagerdal, B.H. and Zacchi, G., Simultaneous saccharification and co-fermentation of glucose and xylose in steam-pretreated corn stover at high fiber content with Saccharomyces cerevisiae TMB3400. J. Biotechnol., 126, 488-498 (2006).

Pan, X.J., Role of functional groups in lignin inhibition of enzymatic hydrolysis of cellulose to glucose. J. Biobased Mater. Bioenergy, 2, 25-32 (2008).

Pereira, J.C., Travaini, R., Marques, N.P., Bolado-Rodriguez, S. and Martins, D.A.B., Saccharification of ozonated sugarcane bagasse using enzymes from Myceliophthora thermophila JCP 1-4 for sugars release and ethanol production. Bioresour. Technol., 204, 122-129 (2016).

Rabelo, S.C., Andrade, R.R., Maciel-Filho, R. and Costa, A.C., Alkaline hydrogen peroxide pretreatment, enzymatic hydrolysis and fermentation of sugarcane bagasse to ethanol. Fuel, 136, 349-357 (2014).

Rabelo, S.C., Fonseca, A.N.A., Andrade, R.R., Maciel-Filho, R. and Costa, A.C., Ethanol production from enzymatic hydrolysis of sugarcane bagasse pretreated with lime and alkaline hydrogen peroxide. Biomass and Bioenergy, 35, 2600-2607 (2011).

Reiner, L., Scanning Electron Microscopy: physics of image Formation and Microanalysis. New York, USA (2010).

Riyajan, S. and Intharit, I., Characterization of Modified Bagasse and Investigation Properties of Its Novel Composite. J. Elastomers Plast., 43, 513-528 (2011).

Rocha, G.J.M., Gonçalves, A.R., Nakanishi, S.C., Nascimento, V.M. and Silva, V.F.N., Pilot scale steam explosion and diluted sulfuric acid pretreatments: comparative study aiming the sugarcane bagasse saccharification. Ind. Crops Prod., 74, 810-816 (2015).

Rocha, M.V.P., Rodrigues, T.H.S., Macedo, G.R. and Gonçalves, L.R.B., Enzymatic Hydrolysis and Fermentation of Pretreated Cashew Apple Bagasse with Alkali and Diluted Sulfuric Acid for Bioethanol Production. Appl. Biochem. Biotechnol., 155, 407-417 (2009).

Ruiz, E., Cara, C., Manzanares, P., Ballesteros, M. and Castro, E., Evaluation of steam explosion pre-treatment for enzymatic 
hydrolysis of sunflower stalks. Enzym. Microbiol. Technol., 42, 160-166 (2008).

Schell, D.J., Farmer, J., Newman, M. and McMillan, J.D., Dilute sulfuric acid pretreatment of corn stover in pilot-scale reactor - investigation of yields, kinetics, and enzymatic digestibilities of solids. Appl. Biochem. Biotechnol., 105, 69-85 (2003).

Selig, M.J., Weiss, N. and Ji, Y., Enzymatic Saccharification of Lignocellulosic Biomass. Renew. Energy (2008).

Sluiter, A., Ruiz, R., Scarlata, C. and Sluiter, L., Determination of Extractives in Biomass (2008).

Smith, B.C., Fundamentals of Fourier transform infrared spectroscopy. Boca Raton, USA: CRC Press (2011).

Sousa, L.C., Chundawat, S.P.S., Balan, V. and Dale, B.E., "Cradleto-grave" assessment of existing lignocellulose pretreatment Technologies. Curr. Opin. Biotechnol., 20, 339-347 (2009).

Sun, Y. and Cheng, J., Hydrolysis of lignocellulosic materials for ethanol production: a review. Bioresour. Technol., 83, 1-11 (2002).

Vancov, T., Alston, A.S., Brown, T. and McIntosh, S., Use of ionic liquids in converting lignocellulosic material to biofuels. Renew. Energy, 45, 1-6 (2012).

Vasquez, M.P., Silva, J.N.C., Souza, M.B.J.R. and Pereira-Jr, N., Enzymatic hydrolysis optimization to ethanol production by simultaneous saccharification and fermentation. Appl. Biochem. Biotechnol., 136-140, 141-154 (2007).

Ximenes, E., Kim, Y., Mosier, N., Dien, B. and Ladisch, M., Inhibition of cellulases by phenols. Enzyme Microb. Technol., 46, 170-176 (2010).
Ximenes, E., Kim, Y., Mosier, N., Dien, B. and Ladisch, M., Deactivation of cellulases by phenols. Enzyme Microb. Technol., 48, 54-60 (2011).

Xu, F., Sun, J., Liu, X.C.F. and Sun, R.C., Comparative study of alkali- and acidic organic solvent-soluble hemicellulosic polysaccharides from sugarcane bagasse. Carbohydr. Res., 34, 1253-1261 (2006).

Yang, P., Guo, L., Cheng, S., Lou, N. and Lin, J., Recombinant multi-functional cellulase activity in submerged fermentation of lignocellulosic wastes. Renew. Energy, 36, 3268-3272 (2011).

Zhang, K., Chang, J., Guan, Y., Chen, H., Yang, Y. and Jiang, J., Lignocellulosic biomass gasification technology in China. Renew. Energy, 49, 175-184 (2013).

Zhao, X., Song, Y. and Liu, D., Enzymatic hydrolysis and simultaneous saccharification and fermentation of alkali/ peracetic acid-pretreated sugarcane bagasse for ethanol and 2,3-butanediol production. Enzym. Microbiol. Technol., 49, 413-419 (2011).

Zhao, X., Zhou, Y., Zheng, G. and Liu, D., Microwave Pretreatment of Substrates for Cellulase Production by SolidState Fermentation. Appl. Biochem. Biotechnol., 160, 15571571 (2010).

Zhou, J., Wang, Y.H., Chu, J., Luo, L.Z., Zhuang, Y.P. and Zhang, S.L., Optimization of cellulase mixture for efficient hydrolysis of steam-exploded corn stover by statistically designed experiments. Bioresour. Technol., 100, 819-825 (2009). 